\title{
Quimio e termoterapia em sementes e aplicação de fungicidas em Brachiaria brizantha como estratégias no manejo do carvão ${ }^{1}$
}

\author{
Carlos Eduardo Marchi ${ }^{1}$, Celso Dornelas Fernandes ${ }^{2,5}$, Fábio Coutinho Anache ${ }^{3}$, Vanessa de Fátima Jerba ${ }^{2}$ \& Larissa \\ Rodrigues Fabris ${ }^{4}$
}

\begin{abstract}
${ }^{1}$ SLaboratório Nacional Agropecuário (LANAGRO-SP), CEP 13208-051, Jundiaí-SP; ${ }^{2}$ Embrapa Gado de Corte, CP 154, CEP 79002-970, Campo Grande, MS; ${ }^{3}$ Universidade para o Desenvolvimento do Estado e da Região do Pantanal (UNIDERP), CP 2153, CEP 79003-010, Campo Grande, MS; ${ }^{4}$ Universidade Federal do Mato Grosso do Sul, CP 549, CEP 79070-900, Campo Grande, MS; ${ }^{5}$ Professor colaborador da UNIDERP; *Apoio: FUNDECT-MS/CNPq.
\end{abstract}

Autor para correspondência: Carlos E. Marchi. E-mail: carlos.marchi@agricultura.gov.br

Data de chegada: 24/05/2006. Aceito para publicação em: 15/05/2008

\section{RESUMO}

Marchi, C.E.; Fernandes, C.D.; Anache, F.C.; Jerba, V. de F; Fabris, L.R. Quimio e termoterapia em sementes e aplicação de fungicidas em Brachiaria brizantha como estratégias no manejo do carvão. Summa Phytopathologica, v.34, n.4, p.321-325, 2008

Objetivou-se estudar os potenciais dos tratamentos térmico e químico em sementes de Brachiaria brizantha cv. Piatã, preconizados como eficientes na superação da dormência física das mesmas, na redução do inóculo de carvão (Ustilago operta). Amostras de sementes foram expostas ao ácido sulfúrico por tempo variando de 0 a $10 \mathrm{~min}$, ou imersas em água à temperatura variável $\left(27\right.$ a $60{ }^{\circ} \mathrm{C}$ ) por 5 ou $10 \mathrm{~min}$. Avaliaram-se os efeitos dos tratamentos no número de teliósporos de $U$. operta remanescentes e na freqüência de germinação das sementes tratadas. À medida que se prolongou a escarificação química das sementes se evidenciou decréscimo do inóculo de carvão. Menor número de teliósporos foi observado nas sementes submetidas à quimioterapia por $10 \mathrm{~min}$. Em geral, a exposição das sementes ao $\mathrm{H}_{2} \mathrm{SO}_{4}$ não levou ao decréscimo da capacidade germinativa das mesmas. Os resultados da termoterapia não foram tão evidentes como os observados para a quimioterapia, sejam na redução do número de teliósporos ou na superação da dormência. É provável que o tempo de exposição das sementes não tenha sido o suficiente. Paralelamente, verificou-se a eficiência da aplicação de fungicidas na parte aérea das plantas no controle da incidência do carvão. Foram testados os fungicidas: 1 - tiofanato metílico + chlorothalonil; 2 - mancozeb; 3 - tebuconazole; 4 triadimenol; 5 - azoxystrobin + cyproconazole; 6 - pyraclostrobin + epoxyconazole; 7 - trifloxystrobin + cyproconazole; 8 - carboxin + thiram; 9 - tiofanato metílico + flutriafol; 10 - carbendazin, e 11 - difenoconazole. Mesmo com a ocorrência de baixa incidência de carvão na área experimental (máximo de 15\%), observaram-se diferenças entre os fungicidas quanto ao controle da doença. O fungicida tebuconazole e as formulações pyraclostrobin + epoxyconazole e trifloxystrobin + cyproconazole foram os mais promissores.

Palavras-chave adicionais: Ustilago operta, tratamento de sementes, controle químico, braquiária.

\section{ABSTRACT}

Marchi, C.E.; Fernandes, C.D.; Anache, F.C.; Jerba, V. de F.; Fabris, L.R. Chemical and thermal therapy in seeds and application of fungicides in Brachiaria brizantha as strategies for managing smut. Summa Phytopathologica, v.34, n.4, p.321-325, 2008

This work investigated the potentials of the thermal and chemical treatments in seeds of Brachiaria brizantha cv. Piatã, which have been described as efficient strategies to overcome the physical dormancy of seeds, in the reduction of smut (Ustilago operta). Samples of seeds were immersed in sulfuric acid for 0 to $10 \mathrm{~min}$, or in hot water $\left(27\right.$ to $\left.60^{\circ} \mathrm{C}\right)$ for 5 or $10 \mathrm{~min}$. The effects of the treatments in the number of remaining teliospores of $U$. operta and in the germination of treated seed have been evaluated. A decrease of inoculum was observed as the time of chemical scarification of seeds was increased. The reduction on the number of teliospores was superior with 10 min of chemotherapy. In general, the exposition to $\mathrm{H}_{2} \mathrm{SO}_{4}$ did not result in a decrease of the germinative power of the seeds. The results of the thermotherapy were not as evident as those observed for the chemotherapy. Reductions on the number of teliospores or on the overcoming of the physical dormancy were less apparent, maybe, because the seeds were not immersed in hot water during enough time. In parallel, the efficiency of the application of fungicides on the aerial part of the plants for the control of the smut incidence was verified. The fungicides tested were as follow: 1 - methylic tiofanato + chlorothalonil; 2 - mancozeb; 3 - tebuconazole; 4 triadimenol; 5 - azoxystrobin + cyproconazole; 6 - pyraclostrobin + epoxyconazole; 7 - trifloxystrobin + cyproconazole; 8 - carboxin + thiram; 9 - methylic tiofanato + flutriafol; 10 - carbendazin, and 11 - difenoconazole. Although the smut incidence observed in the experimental area was low (maximum of $15 \%$ ), a differentiation among the fungicides was possible. The tebuconazole, pyraclostrobin + epoxyconazole and trifloxystrobin + cyproconazole were the most promising fungicides.

Keywords: Ustilago operta, seed treatment, chemical control, braquiaria grass. 
O Brasil é o maior produtor, consumidor e exportador de sementes de gramíneas forrageiras tropicais (2). A quantidade de sementes comercializada está ao redor de 100.000 t/ano, com valor bruto estimado em US\$ 100 milhões (2). Cerca de $95 \%$ do volume total de sementes produzidas é destinado ao comércio interno, sendo que $60 \%$ correspondem às sementes do gênero Brachiaria (19). O restante é exportado principalmente para países da América do Sul e Central (7). Apesar de economicamente expressivo, o sistema de produção de sementes encontra-se ameaçado pela incidência de patógenos nas mesmas, os quais promovem redução da produção e qualidade, além de constituir grandes entraves às exportações brasileiras, devido às barreiras fitossanitárias.

Ustilago operta, agente etiológico da doença conhecida como carvão, constitui exemplo de patógeno capaz de inviabilizar a produção de sementes de gramíneas forrageiras. O fungo foi relatado em $B$. brizantha por Verzignassi et al. em 2001, e a partir daí tem sido freqüentemente constatado em campos de produção de sementes da Embrapa, Gado de Corte, Campo Grande, MS. Baseado na literatura, a doença limita-se a algumas áreas do estado de Mato Grosso do Sul, porém, a falta de padrões de qualidade sanitária para as sementes de forrageiras destinadas para o mercado interno pode facilitar a dispersão do carvão para outras regiões e estados do Brasil.

O carvão é observado tipicamente nas sementes, a qual pode ser totalmente colonizada pelo fungo. Os sintomas/sinais são caracterizados pela presença de massas pulverulentas negras, irrompendo ou não o tegumento das sementes (21). No ano de 2000, em colheita realizada na Embrapa Gado de Corte, cerca de 70\% do lote de sementes de $B$. brizantha cv. Piatã estava comprometido pela ocorrência de carvão (21). Mais recentemente, safra 2004/05, em campos de produção de sementes básicas da mesma cultivar foi constatada incidência de carvão nas sementes da ordem de $64 \%$ (Embrapa Gado de Corte, 2005, dados não publicados).

O controle de $U$. operta em Brachiaria sp. não está definido na literatura. Em geral, o controle químico ainda é desconhecido e a resistência de diferentes braquiárias ao carvão precisa ser melhor elucidada (21). O tratamento de sementes com fungicidas não é utilizado de forma rotineira pelos produtores de sementes, talvez devido à falta de produtos registrados para Brachiaria sp. É possível que os métodos empregados para a superação da dormência física em sementes de braquiária, incluindo a escarificação com ácido sulfúrico e o tratamento com água quente (1), possam constituir importante ferramenta para o manejo de $U$. operta em Brachiaria sp.

Diante dos riscos que o carvão representa para a produção de sementes de $B$. brizantha e da falta de informações acerca do manejo da doença, objetivou-se analisar os potenciais do tratamento de sementes com água quente ou com ácido sulfúrico, bem como da aplicação de fungicidas na parte aérea das plantas, como estratégias no manejo do carvão.

\section{MATERIAL E MÉTODOS}

\section{Obtenção das amostras de sementes}

Sementes básicas de $B$. brizantha cv. Piatã com sintomas/sinais de carvão, provenientes de área de produção da Embrapa Gado de Corte, Campo Grande, MS, safra 2003/04, foram utilizadas para a condução da quimio e termoterapia.

Após a coleta e beneficiamento das sementes, procedeu-se a quantificação da incidência de carvão (\%). Para isso, 400 sementes foram cortadas longitudinalmente, com o auxílio de bisturi, e observadas sob microscópio estereoscópico quanto à presença do fungo.
Anteriormente ao exame visual, as sementes foram submersas em água por $1 \mathrm{~h}$ para facilitar a operação de corte das mesmas. Foram consideradas infectadas as sementes cujos embriões foram substituídos por massas pulverulentas negras, compostas por teliósporos do fungo.

Adicionalmente, as sementes foram submetidas ao teste de germinação, conduzido em caixas tipo gerbox (cinco repetições de 100 sementes), sobre papel germiteste, umedecido com solução de $\mathrm{KNO}_{3}$ a $0,2 \%$. Os gerboxes foram vedados com fita adesiva e acondicionados em câmara germinadora com alternância de temperatura-fotoperíodo $\left(20^{\circ} \mathrm{C}\right.$ sem luz $/ 16$ h e $35^{\circ} \mathrm{C}$ com luz/8 h). Aos 21 dias após incubação procedeu-se a contagem das sementes germinadas. Foram consideradas germinadas as sementes que deram origem a plântulas normais, de acordo com as Regras para Análise de Sementes (3).

\section{Tratamentos de sementes com ácido sulfúrico}

Avaliou-se a eficiência do ácido sulfúrico na redução do inóculo de U. operta em sementes da cv. Piatã com $27 \%$ de incidência do fungo. $\mathrm{O}$ ensaio foi conduzido em delineamento experimental inteiramente casualizado, com 6 tratamentos e 5 repetições.

Amostras de $5 \mathrm{~g}$ de sementes foram imersas em $5 \mathrm{~mL}$ de $\mathrm{H}_{2} \mathrm{SO}_{4}$ comercial (96-98\%) durante $0,2,4,6,8$ ou $10 \mathrm{~min}$. O tratamento controle foi composto por água destilada estéril. Durante o período de tratamento, a suspensão de sementes foi periodicamente agitada.

\section{Tratamento de sementes com água quente}

Avaliou-se o efeito da temperatura, bem como do tempo de exposição, na redução do inóculo de $U$. operta nas sementes da cv. Piatã com $27 \%$ de incidência do fungo. O ensaio foi conduzido em delineamento experimental inteiramente casualizado, em esquema fatorial $4 \times 2$ com 4 repetições.

Amostras de $5 \mathrm{~g}$ de sementes foram colocadas em recipientes de vidro contendo $100 \mathrm{~mL}$ de água destilada, os quais foram mantidos em banho-Maria com temperatura ajustada para 27 (controle), 40, $50 \mathrm{ou}$ $60{ }^{\circ} \mathrm{C}$. Foram testados dois períodos de exposição das sementes ao calor, 5 e 10 min. A suspensão de sementes foi periodicamente agitada.

\section{Quantificação do inóculo de carvão remanescente nas sementes tratadas}

As sementes de braquiária tratadas com ácido sulfúrico ou água quente foram avaliadas quanto ao número de teliósporos de $U$. operta remanescente. Para isso, as sementes tratadas foram trituradas em liquidificador, para a liberação dos teliósporos. O tempo de trituração foi de 3 e 8 min para a quimioterapia e termoterapia, respectivamente. No caso das sementes tratadas com $\mathrm{H}_{2} \mathrm{SO}_{4}$, priori a trituração, foram acrescidos $95 \mathrm{~mL}$ de água destilada.

A suspensão de sementes obtida foi coada em peneira de malha fina, e os teliósporos remanescentes observados em microscópio de luz e quantificados em câmara de Neubauer (10 leituras/repetição).

\section{Avaliação da taxa de germinação das sementes tratadas}

Após o tratamento das sementes, estas foram lavadas em água corrente por 2 min e colocadas para secar em papel toalha por $2 \mathrm{~h}$. Em seguida, de acordo com procedimentos descritos anteriormente, verificou-se a capacidade germinativa das sementes de braquiária submetidas à quimioterapia ou termoterapia.

\section{Aplicação de fungicidas na parte aérea da braquiária}

O ensaio, conduzido no campo experimental da Embrapa Gado de Corte em 2005, foi instalado em blocos ao acaso com quatro repetições, constituídas por parcelas $(5 \times 5 \mathrm{~m})$ de $B$. brizantha cv. Piatã. Os 
seguintes tratamentos, com suas respectivas doses ( $\mathrm{g}$ de i.a./ha), foram analisados: 1 - controle (água); 2 - tiofanato metílico + Chlorothalonil $(400+1000) ; 3$ - mancozeb (2000); 4 - tebuconazole (150); 5 triadimenol (125); 6 - azoxystrobin + cyproconazole $(60+24) ; 7$ pyraclostrobin + epoxyconazole $(99,75+37,50) ; 8$ - trifloxystrobin + cyproconazole $(75+32) ; 9$ - carboxin + thiram $(200+200) ; 10-$ tiofanato metílico + flutriafol $(300+60) ; 11$ - carbendazin (300), e 12 - difenoconazole (75). As combinações de fungicidas consistiram de formulações preparadas comercialmente.

Realizou-se uma aplicação após o lançamento das panículas, e para isso empregou-se pulverizador costal pressurizado com $\mathrm{CO}_{2}$ (pontas tipo leque 110.02 e pressão de $40 \mathrm{lb} / \mathrm{pol}^{2}$ ), aplicando volume de calda de 200L/ha.

Após a colheita das sementes, realizada na parte central da parcela $\left(1 \mathrm{~m}^{2}\right)$ pelo método de varredura, procedeu-se a quantificação da incidência do carvão (\%), estimada a partir de amostras de $1 \mathrm{~g}$ de sementes puras, conforme descrito anteriormente.

Adicionalmente, analisou-se o efeito dos fungicidas na qualidade fisiológica das sementes com base no teste de tetrazólio. Para isso, quatro amostras de 100 sementes, sem sintomas/sinais de carvão, foram embebidas em água durante $10 \mathrm{~h}$. Em seguida, cada semente foi cortada transversalmente próximo ao embrião. A coloração foi feita com solução de tetrazólio $(0,5 \%)$ durante 4 h. Para a avaliação, considerou-se como viável as sementes cujo embrião tornou-se colorido de vermelho. A área máxima permitida de tecido não colorido, flácido ou necrosado foi de 2/3 da radícula, a partir de sua extremidade (3).

\section{Análises dos dados}

As pressuposições da análise de variância foram verificadas por meio de testes de homogeneidade de variância, normalidade e padrão de distribuição de resíduos. Esses procedimentos estatísticos, bem como os demais, foram realizados com o programa SAS (17). Exceção feita ao experimento envolvendo a aplicação de fungicidas, em que as comparações múltiplas entre as médias foram realizadas pelo teste de agrupamento Scott \& Knott (18), disponibilizado no programa Genes (5).

\section{RESULTADOS}

As amostras de sementes de B. brizantha cv. Piatã utilizadas nos ensaios de quimioterapia e termoterapia apresentaram incidência de $U$. operta de $27 \%$ e freqüência de germinação de

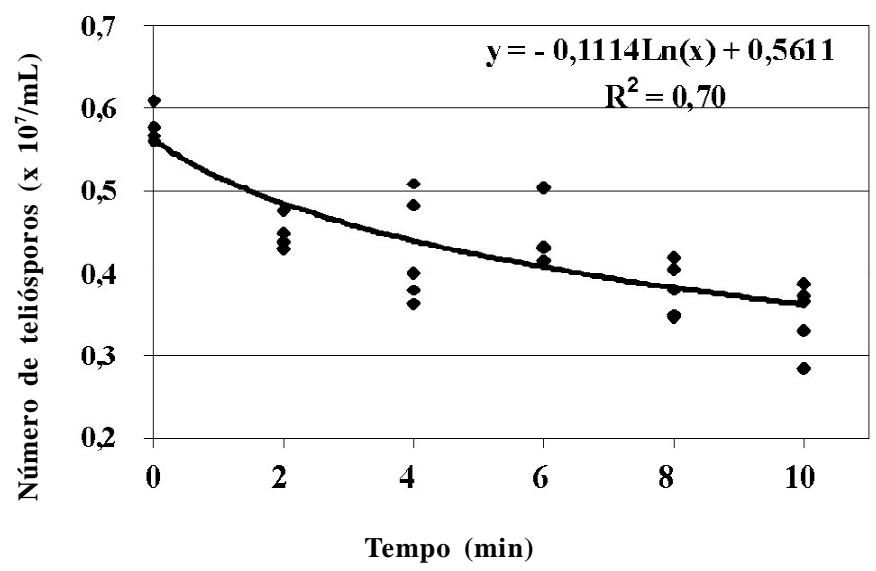

Figura 1. Número de teliósporos de Ustilago operta remanescentes em sementes de Brachiaria brizantha cv. Piatã em função do tempo de imersão

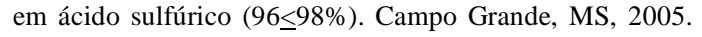

aproximadamente $36 \%$.

O efeito do ácido sulfúrico na redução do inóculo de carvão nas sementes está representado graficamente na Figura 1. No geral, houve tendência de redução do número de teliósporos de $U$. operta à medida que se aumentou o tempo de exposição das sementes ao $\mathrm{H}_{2} \mathrm{SO}_{4}$. As sementes imersas em ácido sulfúrico por 10 min apresentaram o menor número de teliósporos remanescentes (Figura 1).

A exposição das sementes ao $\mathrm{H}_{2} \mathrm{SO}_{4}$ acima de 2 min resultou em aumento da capacidade germinativa das mesmas. Com 4, 6, 8 e 10 min de exposição ao ácido houve, em relação à testemunha, acréscimo de $56,5,92,2,91,2$ e $85,7 \%$ na freqüência de germinação das sementes, respectivamente. Maior freqüência de sementes germinadas foi obtida com a quimioterapia conduzida por 6 min.

A Tabela 1 descreve o efeito do tratamento com água quente na redução do inóculo de carvão e no potencial germinativo das sementes. Não houve interação entre a temperatura da água e o tempo de exposição das sementes.

Fixando-se o fator tempo de exposição das sementes, verificou-se que o aumento da temperatura não influenciou no número de teliósporos de $U$. operta. Em ambos os tempos de exposição, 5 e $10 \mathrm{~min}$, o inóculo de carvão quantificado nas sementes tratadas com água a 40,50 ou $60^{\circ} \mathrm{C}$ foi similar ao observado no tratamento controle $\left(27^{\circ} \mathrm{C}\right)$. Por outro lado, quando se analisaram as temperaturas individualmente, constatou-se que o aumento do tempo de exposição das sementes ao calor promoveu a diminuição do número de teliósporos remanescentes na termoterapia conduzida com água a $50{ }^{\circ} \mathrm{C}$ (Tabela 1$)$.

Tabela 1. Número de teliósporos de Ustilago operta remanescentes em sementes de Brachiaria brizantha cv. Piatã submetidas ao tratamento com água em diferentes temperaturas por 5 ou 10 minutos. Campo Grande, MS, 2005.

\begin{tabular}{clllll}
\hline \multicolumn{7}{c}{ Temperatura $\left({ }^{\circ} \mathbf{C}\right)$} \\
\hline Tempo de exposição (min) & 27 & 40 & 50 & 60 \\
05 & $0,61 *$ aA & 0,66 aA & 0,66 aA & 0,56 aA \\
10 & 0,62 aA & 0,64 aA & 0,50 aB & 0,65 aA \\
\hline
\end{tabular}

* Médias seguidas pela mesma letra minúscula na linha e maiúscula na coluna não diferem entre si pelo teste de Tukey $(P d \geq 0,05)$.

Com relação à capacidade germinativa das sementes submetidas à termoterapia, também não se constatou interação entre a temperatura da água e o tempo de exposição das sementes. Fixando o fator temperatura, não se observou correlação positiva entre o tempo de exposição e a frequiência de germinação das sementes (Tabela 2). Porém, analisando individualmente os tempos de exposição, especificamente os resultados obtidos com a termoterapia conduzida por $5 \mathrm{~min}$, verificou-se decréscimo no potencial germinativo das sementes submetidas ao tratamento com água a $60{ }^{\circ} \mathrm{C}$. Quando se procedeu a

Tabela2. Porcentagem de germinação de sementes de Brachiaria brizantha cv. Piatã submetidas ao tratamento com água em diferentes temperaturas por 5 ou 10 minutos. Campo Grande, MS, 2005.

\begin{tabular}{cllll}
\hline \multicolumn{5}{c}{ Temperatura $\left({ }^{\circ} \mathbf{C}\right)$} \\
\hline Tempo de exposição (min) & 27 & 40 & 50 & 60 \\
05 & 36,10 aA & 39,40 aA & 39,05 aA & 28,55 bA \\
10 & 36,83 abA & 37,60 aA & 35,80 abA & 29,40 bA \\
\hline
\end{tabular}

*Médias seguidas pela mesma letra minúscula na linha e maiúscula na coluna não diferem entre si pelo teste de Tukey $(P d \geq 0,05)$. 
Tabela 3. Fungicidas aplicados na parte aérea de Brachiaria brizantha cv. Piatã, efeito no controle da incidência de Ustilago operta e na viabilidade das sementes. Campo Grande, MS, 2005.

\begin{tabular}{lcccc}
\hline Tratamentos & $\begin{array}{c}\text { Incidência de } \\
\text { carvão }\end{array}$ & \multicolumn{2}{c}{$\begin{array}{c}\text { Viabilidade das } \\
\text { sementes (\%) }\end{array}$} \\
\hline Controle (água) & $9,76^{*}$ & b & 73,7 & a \\
Tiofanato metílico + Chlorothalonil & 14,65 & a & 70,2 & a \\
Mancozeb & 4,90 & c & 74,5 & a \\
Tebuconazole & 2,47 & d & 80,6 & a \\
Triadimenol & 5,88 & c & 79,9 & a \\
Azoxystrobin + Cyproconazole & 5,54 & c & 72,4 & a \\
Pyraclostrobin + Epoxyconazole & 3,48 & d & 77,9 & a \\
Trifloxystrobin + Cyproconazole & 1,43 & d & 82,0 & a \\
Carboxin + Thiram & 4,18 & c & 73,1 & a \\
Tiofanato metílico + Flutriafol & 5,49 & c & 73,8 & a \\
Carbendazin & 5,87 & c & 75,5 & a \\
Difenoconazole & 6,70 & c & 77,3 & a \\
\hline
\end{tabular}

*Valores representam médias de quatro repetições e seguidos pela mesma letra não diferem pelo teste de agrupamento Scott-Knott $(P d \geq 0,05)$.

termoterapia por $10 \mathrm{~min}$, em termos absolutos, também se observou redução da freqüência de sementes germinadas quando estas foram imersas em água a $60^{\circ} \mathrm{C}$ (Tabela 2).

O resultado do ensaio conduzido para avaliar a contribuição da aplicação de fungicidas na parte aérea das plantas no manejo do carvão está descrito na Tabela 3. Observou-se baixa incidência de carvão no campo experimental. O maior índice médio registrado foi de aproximadamente $15 \%$ (Tabela 3).

Com exceção da formulação tiofanato metílico + chlorothalonil, todos os demais fungicidas superaram a testemunha (Tabela 3). Em geral, os fungicidas também se diferenciaram entre si quanto ao controle de $U$. operta nas sementes da braquiária.

A maior parte dos fungicidas reduziu o inóculo de carvão das sementes em torno de 31 a $57 \%$, quando comparado à testemunha (Tabela 3). No entanto, a aplicação do fungicida tebuconazole ou das formulações pyraclostrobin + epoxyconazole ou trifloxystrobin + cyproconazole promoveu controle ainda mais eficiente da doença. Trifloxystrobin + cyproconazole, por exemplo, resultou em incidência de carvão inferior a 1,5\% (Tabela 3 ).

$\mathrm{O}$ resultado do teste de tetrazólio indicou que os fungicidas não afetaram a qualidade fisiológica das sementes. Em geral, as amostras de sementes da braquiária obtidas a partir de cada tratamento apresentaram semelhantes graus de viabilidade, os quais variaram de 70 a $82 \%$ (Tabela 3 ).

\section{DISCUSSÃO}

Como esperado, a escarificação das sementes de $B$. brizantha cv. Piatã com ácido sulfúrico resultou em aumento da taxa de germinação. Essa estratégia já havia sido empregada com sucesso em $B$. brizantha (13), e em outras espécies como B. decumbens (4) e B. dictyoneura (1).

Com relação à redução do inóculo de $U$. operta nas sementes de $B$. brizantha cv. Piatã, o tratamento com $\mathrm{H}_{2} \mathrm{SO}_{4}$ apresentou efeito positivo. Porém, o tempo de exposição das sementes deve ser determinado com cautela, pois pode influenciar negativamente na germinação das sementes. A exposição prolongada ao ácido sulfúrico pode induzir danos fisiológicos nas sementes, conforme observado por Freitas et al. (9). Os resultados dessa pesquisa não demonstraram claramente esta tendência, talvez porque o período de exposição das sementes ao $\mathrm{H}_{2} \mathrm{SO}_{4}$ não excedeu o limite crítico.

Por sua vez, o efeito do calor na superação da dormência física das sementes não foi tão evidente quanto ao obtido com a escarificação química. Os resultados divergiram daqueles observados anteriormente para $B$. brizantha $\mathrm{cv}$. Marandu (11), provavelmente devido ao pouco tempo de exposição das sementes ao calor (máximo de $10 \mathrm{~min}$ ). Em geral, reduções na taxa de dormência e efeitos positivos no desempenho das sementes de braquiária têm sido obtidos com a termoterapia conduzida por 10 a $15 \mathrm{~h}(1 ; 10)$.

Assim como mencionado para a escarificação química, é de suma importância a determinação correta do tempo de exposição das sementes ao calor. A mesma preocupação deve ser aplicada à escolha da temperatura da água. Tratamentos conduzidos com temperaturas muito elevadas, apesar de reduzir a taxa de dormência das sementes, podem prejudicar fisiologicamente as mesmas, retardando o processo germinativo (6), ou até mesmo comprometendo a viabilidade da semente. Martins \& Silva $(10 ; 12)$ verificaram tais efeitos negativos, tanto para as sementes de Panicum maximum quanto de $B$. brizantha. Também para as sementes da cv. Piatã constatou-se influência negativa da termoterapia conduzida com temperatura alta $\left(60^{\circ} \mathrm{C}\right)$, caracterizada por redução da capacidade germinativa.

Em cana-de-açúcar, a termoterapia constitui medida auxiliar recomendada para o controle de carvão, U. scitaminea (20). Contudo, os tratamentos de imersão das sementes de braquiária em água quente pouco influíram no inóculo de U. operta. Em geral, o aumento do tempo da termoterapia das sementes e/ou da temperatura não promoveu a redução do número de teliósporos de carvão remanescentes. Tal resposta também pode ter sido devido ao período reduzido de exposição das sementes ao calor, ou pela relativa resistência dos teliósporos às temperaturas analisadas. Parisi et al. (15), realizando estudos com sementes de B. brizantha cv. Marandu, já haviam observado a resistência de determinados fungos a elevadas temperaturas e tempos de exposição ao calor.

Para validar a escarificação de sementes com ácido sulfúrico como prática de manejo do carvão em braquiárias, ensaios posteriores deverão ser conduzidos com o intuito de se verificar o efeito do $\mathrm{H}_{2} \mathrm{SO}_{4}$ na viabilidade dos teliósporos, pois, embora tenha sido significativa a redução dos teliósporos de $U$. operta, é possível que o inóculo remanescente seja capaz de desencadear epidemia no campo. Raciocínio similar deve ser estendido à termoterapia. Apesar dos tratamentos com água quente não terem sido eficientes na redução do número de teliósporos, é possível que tenham inviabilizado o inóculo remanescente.

Quanto ao potencial de controle do carvão mediante a aplicação de fungicida na parte aérea das plantas, foram obtidos resultados promissores. Mesmo tendo sido baixo o nível de doenças na área experimental, ao contrário do observado em campo de produção de sementes básicas na referida unidade de pesquisa, foi possível diferenciar os fungicidas em relação ao controle do patógeno. Em geral, quando aplicados na parte aérea da braquiária, os fungicidas contribuíram para a redução da incidência de carvão nas sementes, sem, contudo, afetar a qualidade fisiológica das sementes. Exceção feita ao tiofanato metílico + chlorothalonil, cuja aplicação resultou em maior incidência de sementes infectadas pelo patógeno. É possível que, de alguma forma, esta formulação aumentou a predisposição do hospedeiro à doença. 
Os produtos mais promissores foram o tebuconazole, pyraclostrobin + epoxyconazole e trifloxystrobin + cyproconazole, os quais reduziram a ocorrência de $U$. operta nas sementes em 75, 64 e $85 \%$, respectivamente. O tebuconazole e outros fungicidas promissores como difeconazole, thiram + carboxin e triadimenol, também foram descritos como eficientes no controle de Ustilago spp. em cevada e trigo, contudo, mediante o tratamento de sementes $(8 ; 14$; 16). Especificamente para o carvão da braquiária, U. operta, não foram encontrados relatos sobre o controle químico, seja por meio do tratamento de sementes ou da aplicação de fungicidas na parte aérea das plantas.

Apesar do potencial dessa estratégia, antes da aplicação de fungicidas na parte aérea das plantas constituir componente de programas de manejo integrado do carvão da braquiária, será necessário avaliar a eficiência desses e outros produtos em condições de elevado nível de doença. Uma vez comprovada a eficiência, essa prática poderá constituir importante medida auxiliar para a erradicação do carvão, ou para reduzir o patógeno em níveis aceitáveis.

\section{REFERÊNCIAS BIBLIOGRÁFICAS}

1. Almeida, C.R. de; Silva, W.R. da. Comportamento da dormência em sementes de Brachiaria dictyoneura cv.Llanero submetidas às ações do calor e do ácido sulfúrico. Revista Brasileira de Sementes, Pelotas, v.26, n.1, p.44-49, 2004.

2. ANDRADE, R.P. de; VILLAS BOAS, H.D.; SILVEIRA, G.C.; PAIVA, L. A parceria EMBRAPA-UNIPASTOS e seu impacto na pesquisa e desenvolvimento de pastagens tropicais do Brasil. 2004. Disponível em: <http://www.abrasem.com.br/ materia_tecnica/2004/0008_parceria_embrapa_unipastos.htm >. Acesso em: 22 abr. 2006.

3. Brasil. Ministério da Agricultura e Reforma Agrária. Secretaria Nacional de Defesa Agropecuária. Regras para Análise de Sementes. Brasília, 1992. 365 p.

4. Castro, C.R.T.; Carvalho, W.L.; Reis, F.P.; Braga Filho, J.M. Superação da dormência tegumentar em sementes de Brachiaria decumbens Stapf. Revista Ceres, Viçosa, v.43, n.245, p.67-75, 1996.

5. Cruz, C.D. Programa genes: aplicativo computacional em genética e estatística. Viçosa: UFV, 2001. 648p.

6. Dhingra, O.D.; Muchovej, J.J.; Filho, J.C. Tratamento de sementes: controle de patógenos. Viçosa, UFV, 1980. 106p.

7. Fernandes, C.D.F.; Marchi, C.E.; Jerba, V. de F.; Borges, M. de F. Patógenos associados às sementes de forrageiras tropicais e estratégias de controle. In: Zambolim, L. (Ed.). Sementes: qualidade fitossanitária. Viçosa: UFV, 2005. p.183-213
8. Forcelini, C.A.; Reis, E.M. Doenças da cevada. In: Kimati, H.; Amorim, L.; Bergamin Filho, A.; Camargo, L.E.A.; Rezende, J.A.M. (Ed.). Manual de fitopatologia, 3. ed.. São Paulo: Agronômica Ceres, 1997. p.251-256.

9. Freitas, R.R. de; Carvalho, D.A. de; Alvarenga, A.A. de. Quebra de dormência e germinação de sementes de capim-marmelada [Brachiaria plantaginea (Link) Hitch]. Revista Brasileira de Fisiologia Vegetal, Londrina, v.2, n.2, p.31-35, 1990.

10. Martins, L.; Silva, W.R. Comportamento da dormência em sementes de braquiária submetidas a tratamentos térmicos e químicos. Pesquisa Agropecuária Brasileira, Brasília, v. 36, n. 7, p.997-1003, 2001.

11. Martins, L.; Silva, W.R. Efeitos imediatos e latentes de tratamentos térmico e químico em sementes de Brachiaria brizantha cultivar Marandu. Bragantia, Campinas, v.62, n.1, p.81-88, 2003.

12. Martins, C.C.; Silva, W.R. Superação de dormência em sementes de Panicum maximum Jacq.: seleção de métodos para aplicação em escala industrial. Planta Daninha, Rio de Janeiro, v.16, n.2, p.77-84, 1998.

13. Martins, L.; Silva, W.R; Lot, R.C.; Malavolta, V.M. Tratamentos térmicos e superação da dormência em sementes de Brachiaria brizantha (Hoechst. ex A. Rich) Stapf. Informativo ABRATES, Curitiba, v.7, n.1/2, p.245, 1997.

14. Minella, E. Cultivo de cevada. Sistema de produção, Embrapa Trigo, n. 2, 2005. Disponível em: <http:// sistemasdeproducao.cnptia.embrapa.br/FontesHTML/ Cevada/ CultivodeCevada/index.htm>. Acesso em: 19 mai. 2006.

15. Parisi, J.J.D.; Martins, L.; Silva, W.R. da. Incidência de fungos em sementes de Brachiaria brizantha submetidas a tratamentos térmico e ácido sulfúrico. Fitopatologia Brasileira, Fortaleza, v.26, supl., p.338, 2001.

16. Reunião da Comissão Sul-Brasileira de Pesquisa de Trigo, 36., 2004,. Recomendações... Passo Fundo: Comissão Sul-Brasileira de Pesquisa de Trigo, 2004. 150p.

17. Sas Institute. SAS® User's guide: statistics. Cary, 2002.

18. Scott, A.J.; Knott, M.A. Cluster analysis method for grouping means in the analysis of variance. Biometrics, Washington, v. 30, p.507-512, 1974.

19. Souza, F.H.D. de. Produção e comercialização de sementes de plantas forrageiras tropicais no Brasil. In: SIMPÓSIO DE FORRAGiCUltura E PAStAGEnS, 2., 2001, Lavras. Anais... Lavras: Núcleo de Estudos em Forragicultura da UFLA, 2001. p. 273-282.

20. Tokeshi, H. Doenças da cana-de-açúcar. In: Kimati, H.; Amorim, L.; Bergamin Filho, A.; Camargo, L.E.A.; Rezende, J.A.M. (Ed.). Manual de fitopatologia, 3. ed. São Paulo: Agronômica Ceres. 1997. p.207-225.

21. Verzignassi, J.R.; Urben, A.F.; Fernandes, C.D. Ocorrência de $U s$ tilago operta em sementes de Brachiaria brizantha no Brasil. Fitopatologia Brasileira, Fortaleza, v.26, supl., p.423, 2001. 